В. Д. Карлов ${ }^{1}$, О. Л. Кузнєцов ${ }^{1}$, А. М. Артеменко ${ }^{2}$ А. Д. Карлов ${ }^{1}$

${ }^{1}$ Харківський національний університет Повітряних Сил імені Івана Кожедуба, Харків, Україна

${ }^{2}$ Генеральний штаб Збройних Сил України, Київ, Україна

\title{
ПОМИЛКА ВИМІРЮВАННЯ РАДІАЛЬНОЇ ШВИДКОСТІ ЦЛЛ ВНАСЛІДОК ВПЛИВУ ФЛУКТУАЦІЙ ПОЧАТКОВИХ ФАЗ РАДІОІМПУЛЬСІВ ПАЧКИ
}

\begin{abstract}
У статті розглядаються питання оцінювання радіальної швидкості при використанні когерентної пачки радіоімпульсів стосовно випадку наявності у відбитих від цілі радіоімпульсах корельованих флуктуацій початкових фаз. Оцінюється точність вимірювання частоти пачки для випадку узгодженої обробки без врахування фазових флуктуацій іiі радіоімпульсів. Розгляд проводиться у припущенні, що на вхід приймального пристрою РЛС надходить адитивна суміш відбитих від цілей сигналів й некорельованого гаусівського шуму. Вважається, що фазові флуктуації радіоімпульсів прийнятої пачки розподілені за нормальним законом с нульовим середнім, а кореляція фазових флуктуацій зі збільшенням інтервалу між радіоімпульсами пачки убуває за експоненціальним або знакозмінним законами. Наведений аналіз дозволяє визначити умови, при яких ускладнення алгоритму обробки даного радіолокаційного сигналу вважається виправданим.
\end{abstract}

Ключ ов і слов а: когерентно-імпульсна РЛС, пачка радіоімпульсів, фазові флуктуації, радіальна швидкість, гаусівський шум, радіолокаційне спостереження, ефективність оптимізації.

\section{Вступ}

Постановка проблеми. Вдосконалення та розвиток сучасних аеродинамічних об'єктів радіолокаційного спостереження обумовлюють підвищення вимог до засобів їх виявлення та супроводження. Зростання маневрених можливостей цілей та спроможностей виконання ними завдань за призначенням на малих та гранично малих висотах 3 огинанням рельєфу місцевості обумовлює необхідність оцінювання радіолокаторами різних класів похідних дальності до цілі з якомога високою точністю.

Визначення радіальної швидкості цілі протягом первинної часо-частотної обробки радіолокаційної інформації реалізовано в когерентно-імпульсних РЛС, які в якості зондувального сигналу використовують когерентну пачку радіоімпульсів. Ступінь когерентності даної пачки визначає тривалість іiі закономірної фазової структури i, як слід, міру роздільної здатності РЛС за радіальною швидкістю та точність вимірювання радіальної швидкості повітряного об'єкта.

Реальні умови поширення та відбиття радіолокаційного сигналу здатні суттєво обмежувати його часову когерентність та якість його часо-частотної обробки. До вказаних умов можна віднести вплив атмосферних неоднорідностей [1-3], доплерівський шум цілі $[4,5,6]$ та відбиття радіохвиль від земної поверхні зі складним рельєфом місцевості $[7,8,9]$.

Оцінка можливого зниження точності вимірювання радіальної швидкості цілі за рахунок фазових флуктуацій сигналу дозволить визначити умови доцільності оптимізації його обробки.

Аналіз останніх досліджень і публікацій.

Радіолокаційному спостереженню цілей та вимірюванню їх координат й параметрів руху в складних умовах присвячена значна кількість робіт.

Спотворення фазової структури радіолокаційного сигналу мають різну природу виникнення. Флуктуації фази, обумовлені наявністю атмосферних неоднорідностей та особливості застосування радіотех- нічних систем в умовах їхнього впливу описані в роботах $[1,7,10,12]$. Окрім цього, складна форма цілі та здатність до виконання раптового маневру, обумовлює блукання іiі радіолокаційного центру та, як слід, появи фазових викривлень прийнятого сигналу та швидкісних шумів цілі $[1,4,5,13,14]$. Якщо радіолокаційне спостереження реалізується по цілям, що рухаються під малими кутами місця, та внаслідок багатотрасового поширення радіолокаційного сигналу з'являються його додаткові фазові викривлення, що розглядаються у $[4,7,8,15,16]$.

В сучасних когерентно-імпульсних РЛС з цифровою обробкою для забезпечення радіолокаційного спостереження складних маневруючих цілей використовується когерентна пачка радіоімпульсів. Тому, має практичну користь оцінювання помилок вимірювання радіальної швидкості цілі в залежності від статистичних характеристик фазових флуктуацій радіоімпульсів прийнятої пачки.

Методика розрахунку помилки вимірювання частоти пачки, що виникає внаслідок впливу фазових флуктуацій іiі радіоімпульсів наведена у $[17,18]$. Як показано в роботі $[19,20]$, можливі значення помилки вимірювання радіальної швидкості цілі, які виникають внаслідок фазових спотворень пачки радіоімпульсів здатні перевищувати допустимі значення РЛС різних діапазонів довжин хвиль.

Метою статті $\epsilon$ аналіз впливу статистичних характеристик флуктуацій початкових фаз радіоімпульсів прийнятої когерентної пачки на зниження точності вимірювання радіальної швидкості цілі.

\section{Основний матеріал}

Оцінювання радіальної швидкості цілі здійснюється згідно з виразом $[1,2]$ :

$$
V_{r}=(\lambda /(4 \pi)) \cdot \Omega,
$$

де $\Omega=2 \pi F_{\partial}$ - циклічний доплерівський зсув частоти; $F_{\partial}$ - частота Доплера; $\lambda$ - довжина хвилі радіолокаційного сигналу. 
Нижче отримаємо вираз дисперсії загальної помилки вимірювання $\sigma_{\Sigma}^{2}$ для прямокутної пачки радіоімпульсів.

Припускається, що прийнята реалізація представляє собою суму відбитої від цілі пачки радіоімпульсів та внутрішнього шуму приймального пристрою

$$
y(t, \Omega)=x(t, \Omega)+n(t),
$$

де $y(t, \Omega)$ - реалізація прийнятого коливання; $x(t, \Omega)$ - реалізація корисного сигналу; $n(t)$ - реалізація внутрішнього гаусівського шуму.

Корисним сигналом $є$ когерентна пачка радіоімпульсів 3 випадковою амплітудою і початковою фазою, комплексна амплітуда якої описується вира30M

$$
X(t, \Omega)=b \sum_{i=1}^{n} X_{i}(t, \Omega) \exp [j(\beta)],
$$

де $X_{i}(t, \Omega)$ - комплексна амплітуда $i$ - го радіоімпульсу; $b$ - випадкова амплітуда радіосигналу, яка розподілена за законом Релея; $\beta$ - випадкова початкова фаза радіосигналу, яка розподілена за рівномірним законом; $i$ - номер радіоімпульсу, який відлічується від початку пачки; $n$ - число радіоімпульсів в пачці.

В роботі [1] визначено, що відношення правдоподібності для когерентного сигналу 3 рівномірно розподіленою випадковою фазою й випадковою амплітудою, розподіленою за законом Релея, як результат статистичного усереднення за випадковими параметрами $b$ і $\beta$ має вид

$$
(\Omega)=\frac{1}{1+q^{2} / 2} \exp \frac{q^{2} / 2}{2\left(1+q^{2} / 2\right)}\left|Z_{H}(\Omega)\right|^{2},
$$

де $q^{2}$ - відношення сигнал-шум за потужністю; $\left|Z_{H}(\Omega)\right|^{2}$ - квадрат модулю нормованого комплексного вагового інтеграла як функція вимірюваного параметра.

В умовах регулярного вимірювання $\left(q^{2}>>1\right)$ справедливою є рівність

$$
\left|Z_{H}(\Omega)\right|=\left|Z_{H}\left(\Phi_{c}, \Phi_{o}\right)\right| \approx q \rho\left(\Phi_{c} \Phi_{o}\right)=q \rho(\Omega),
$$

де $\Phi_{c}=\left\|\Phi_{c i}\right\|^{T}(i=1,2, \ldots, n)$ - вектор спостережуваних значень початкових фаз радіоімпульсів пачки; $\Phi_{o}=\left\|\Phi_{o i}\right\|^{T}$ - вектор очікуваних значень початкових фаз радіоімпульсів пачки; $\rho\left(\Phi_{c}, \Phi_{o}\right)=$ $=\rho(\Omega)-$ нормована функція розузгодження за початковою фазою спостережуваного та очікуваного радіосигналу.

3 урахуванням (5) відношення правдоподібності (4) при $q^{2}>>1$ приймає вигляд

$$
(\Omega) \approx \frac{2}{q^{2}} \exp \frac{q^{2} \rho^{2}(\Omega)}{2} .
$$

Як показано в [17], у випадку когерентної пачки $з$ постійним періодом слідування радіоімпульсів квадрат нормованої функції розузгодження за частотою описується виразом

$$
\begin{gathered}
\rho^{2}(\Omega)=1-\frac{1}{2} \sum_{i=1}^{n} \sum_{j=1}^{n} \xi_{i} \xi_{j}\left(\Phi_{i}-\Phi_{j}\right)^{2}- \\
-\frac{1}{2} T^{2} \Omega^{2} \sum_{i=1}^{n} \sum_{j=1}^{n} \xi_{i} \xi_{j}(i-j)^{2}+ \\
+T \Omega \sum_{i=1}^{n} \sum_{j=1}^{n} \xi_{i} \xi_{j}(i-j)\left(\Phi_{i}-\Phi_{j}\right),
\end{gathered}
$$

де $\Omega=\omega-\omega_{0}$ - розузгодження між очікуваною $\omega$ й спостережуваною $\omega_{0}$ циклічними частотами пачки імпульсів; $i, j$ - номери імпульсів, які відлічуються від початку пачки; $\Phi_{i}, \Phi_{j}$ - спостережувані значення початкової фази $i$-го і ј-го радіоімпульсів відповідно; $\quad \xi_{i}=\frac{Z_{i}}{Z_{\Sigma}} ; \quad Z_{i}=\frac{1}{2}\left|\int_{-\infty}^{\infty} Y_{i}(t) X_{i}^{*}(t) d t\right|$ - модуль сигнальної частини комплексного кореляційного інтеграла для $i$-го радіоімпульсу; $\mathrm{Y}_{i}(t)$ - комплексна обвідна прийнятого $i$-го радіоімпульсу; $\mathrm{X}_{i}^{*}(t)$ комплексно спряжена обвідна опорної напруги при обробці і-го радіоімпульсу; $\mathrm{Z}_{\Sigma}=\sum_{i=1}^{n} \mathrm{Z}_{i} ; \quad T$ - період слідування радіоімпульсів пачки.

Згідно [1] визначено, що оцінювання доплеровського зсуву частоти пачки радіоімпульсів може бути здійснено шляхом знаходження аргументу максимуму натурального логарифму відношення правдоподібності (6)

$$
\Omega=\arg \max \ln (\Omega) .
$$

Для симетричного амплітудного розподілу радіоімпульсів в пачці $\xi_{i}=\xi_{n+1-i}$, підставляючи вираз (7) у вираз (6), логарифмуючи й залишаючи тільки залежні від вимірюваних параметрів доданки, одержуємо вираз для достатньої статистики

$$
\begin{aligned}
S(\Omega)= & \ln (\Omega)=-\frac{q^{2}}{2}\left\{\frac{T^{2}}{2} \Omega^{2} \sum_{i=1}^{n} \sum_{j=1}^{n} \xi_{i} \xi_{j}(i-j)^{2}-\right. \\
& \left.-T \Omega \sum_{i=1}^{n} \sum_{j=1}^{n} \xi_{i} \xi_{k}(i-j)\left(\Phi_{i}-\Phi_{j}\right)\right\} .
\end{aligned}
$$

Оцінка і дисперсія помилки оцінювання частоти пачки радіоімпульсів отримується згідно методу найбільшої правдоподібності [1] за виразами:

$$
\frac{d S(\Omega)}{d \Omega}=0 \text { при } \Omega=\Omega,
$$




$$
\frac{1}{\sigma_{\Omega}^{2}}=-\frac{d^{2} \ln (\Omega)}{d \Omega^{2}}=-\frac{d^{2} S(\Omega)}{d \Omega^{2}} \text { при } \Omega=\Omega,
$$

де $\ln (\Omega)$ - натуральний логарифм відношення правдоподібності (6) або його достатньої статистики $S(\Omega) ; \Omega$ - оцінка частоти пачки радіоімпульсів.

Після одноразового і дворазового диференціювання по вимірюваному параметру достатньої статистики (9) одержуються оцінка і дисперсія помилки оцінювання частоти в такому вигляді

$$
\begin{gathered}
\Omega=\sum_{j=1}^{m} \xi_{j}(2 j-1) R_{j} / T \sum_{j=1}^{m} \xi_{j}(2 j-1)^{2}, \\
\frac{1}{\sigma_{\Omega}^{2}}=\frac{q^{2} T^{2}}{2} \sum_{j=1}^{m} \xi_{j}(2 j-1)^{2},
\end{gathered}
$$

де $R_{j}$ - різниця початкових фаз $j$-ої симетричної пари радіоімпульсів; $\mathrm{m}$ - число пар радіоімпульсів, симетричних відносно центру пачки.

Якщо пачка радіоімпульсів має прямокутну, обвідну $\left(\xi_{i}=\frac{1}{n}\right)$, вирази (12) і (13) можна перетворити до виду

$$
\begin{gathered}
\Omega=\frac{3}{m\left(4 m^{2}-1\right) T} \sum_{j=1}^{m}(2 j-1) R_{j}, \\
\frac{1}{\sigma_{\Omega}^{2}}=\frac{q^{2}\left(4 m^{2}-1\right)}{12} T^{2} .
\end{gathered}
$$

Випадкова помилка виміру частоти, обумовлена флуктуаціями початкових фаз імпульсів пачки може бути представлена виразом

$$
\Delta \Omega=\frac{3}{m\left(4 m^{2}-1\right) T} \sum_{j=1}^{m}(2 j-1) \Delta R_{j} .
$$

де $\Delta R_{j}$ - флуктуації різниці фаз ј-ої симетричної пари радіоімпульсів.

Дисперсія цієї помилки визначається виразом

$$
\sigma_{\Omega \phi л}^{2}=\frac{9}{m^{2}\left(4 m^{2}-1\right)^{2} T^{2}}\left\langle\left[\sum_{j=1}^{m}(2 j-1) \Delta R_{j}\right]^{2}\right\rangle .
$$

де \langle\rangle - операція статистичного усереднення.

Дисперсія загальної помилки вимірювання частоти пачки радіоімпульсів визначається сумою дисперсії $\sigma_{\Omega}^{2}$ помилки (15) обумовленої впливом внутрішніх шумів приймального пристрою й дисперсії $\sigma_{\Omega \phi л}^{2}$ помилки (17), викликаної фазовими флуктуаціями радіоімпульсів пачки

$$
\sigma_{\Sigma}^{2}=\sigma_{\Omega}^{2}+\sigma_{\Omega \phi \lambda}^{2}
$$

Вважається, що фазові флуктуації радіоімпульсів прийнятої пачки розподілені за нормальним за- коном с нульовим середнім, а кореляція фазових флуктуацій сусідніх радіоімпульсів пачки убуває за експоненціальним або за знакозмінним законом [1].

Реалізація статистичного усереднення (17) дозволяє отримати вираз дисперсії загальної помилки вимірювання частоти пачки радіоімпульсів

$$
\begin{aligned}
& \sigma_{\Sigma}^{2}=\frac{12}{q^{2} T^{2}\left(4 m^{2}-1\right)}+\frac{18 \sigma_{\varphi}^{2}}{m^{2} T^{2}\left(4 m^{2}-1\right)^{2}} \times \\
& \times\left[\sum_{k=1}^{m}(2 k-1)^{2}\left(1-a^{(2 k-1)}\right)+\right. \\
& \left.+2 \sum_{k=1}^{m-1} \sum_{i=1}^{m-k} a^{i}(2 k-1)(2 k+2 i-1)\left(1-a^{(2 k-1)}\right)\right],
\end{aligned}
$$

де $\sigma_{\varphi}^{2}$ - дисперсія фазових флуктуацій; $a$ - коефіцієнт кореляції фазових флуктуацій сусідніх радіоімпульсів пачки.

На рис. 1 надані графіки залежності добутку квадрата загальної середньоквадратичної помилки вимірювання частоти пачки 3 десяти радіоімпульсів і періоду їх слідування $\left(\sigma_{\Sigma} T\right)^{2}$.
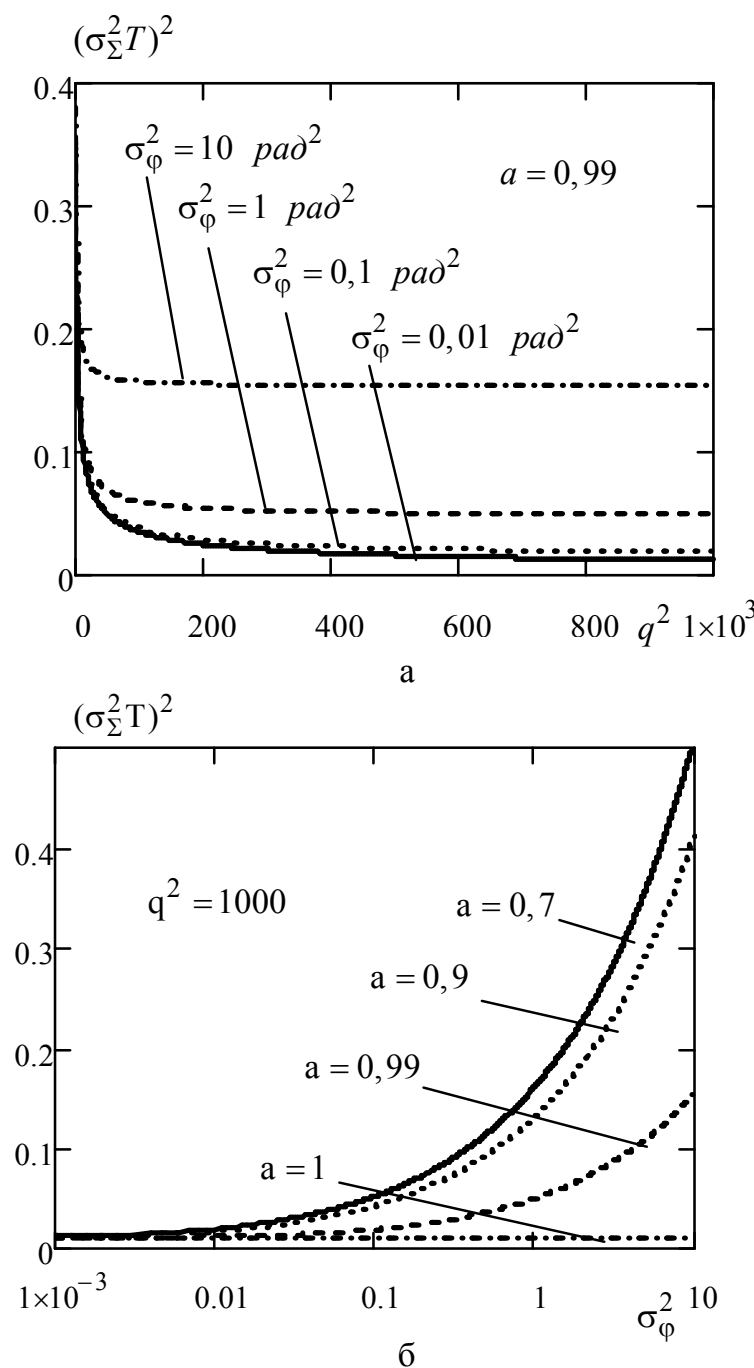

Рис. 1. Дисперсія помилки вимірювання частоти пачки радіоімпульсів при відсутності врахування фазових флуктуацій 
Період слідування $\left(\sigma_{\Sigma} T\right)^{2}$, отриманий згідно (19), залежить від відношення сигнал-шум по потужності $q^{2}$ (рис 1, а) та від дисперсії фазових флуктуацій (рис.1,б) при експоненціальному законі убування їх кореляції в межах пачки радіоімпульсів.

Графіки на рис. 1, а отримані для коефіцієнта міжімпульсної кореляції фазових флуктуацій $a=0,99$ та різних значень дисперсії фазових флуктуацій $\sigma_{\varphi}^{2}=0,01 ; 0,1 ; 1 ; 10$ рад ${ }^{2}$.

Графіки на рис. 1, б отримані для відношення сигнал-шум за потужністю $q^{2}=1000$ та різних значень коефіцієнта міжімпульсної кореляції фазових флуктуацій $a=0,7 ; 0,9 ; 0,99 ; 1$.

Результати наведені на рис. 1,а вказують на те, що в умовах регулярного вимірювання (при $q^{2}>>1$ ), точність вимірювання частоти пачки радіоімпульсів в значно більшому ступені залежить від статистичних характеристик фазових флуктуацій ніж від відношення сигнал-шум.

При незначному впливі фазових флуктуації, збільшення їх дисперсії на порядок в області малих значень $\left(\sigma_{\varphi}^{2}=0,01 \ldots 0,1\right.$ рад $\left.{ }^{2}\right)$ майже не впливає на зміну величини дисперсії помилки вимірювання частоти пачки радіоімпульсів. При значному впливі фазових флуктуацій, збільшення їх дисперсії на порядок в області суттєвих значень $\left(\sigma_{\varphi}^{2}=1 \ldots 10\right.$ pad $\left.^{2}\right)$, які можуть мати місце в реальних умовах виконання РЛС завдань за призначенням, призводить до зростання дисперсії помилки вимірювання частоти пачки радіоімпульсів на порядок і більше. Дані результати отримані при зменшенні коефіцієнта міжімпульсної кореляції фазових флуктуації лише на $1 \%$ $(a=0,99)$.
Графіки на рис. 1, б вказують на те, що при незначних величинах дисперсії фазових флуктуацій $\left(\sigma_{\varphi}^{2}=0,01 \ldots 0,1\right.$ рад $\left.{ }^{2}\right)$, зменшення коефіцієнту їх міжімпульсної кореляції на десятки відсотків в діапазоні значень $a=1 \ldots 0,7$ не суттєво впливає на величину дисперсії помилки вимірювання частоти пачки радіоімпульсів у порівняння з випадком відсутності впливу фазових флуктуацій (при $a=1$ ). При значних величинах дисперсії фазових флуктуацій $\left(\sigma_{\varphi}^{2}=1 \ldots 10 p a \partial^{2}\right)$, дисперсія помилки вимірювання частоти пачки радіоімпульсів здатна зростати в десятки разів, причому найбільш яскраво це проявляється при зменшенні коефіцієнта міжімпульсної кореляції на $1 \ldots 10 \%(a=0,99 \ldots 0,9)$, що дійсно може мати місце в практичних випадках.

Таким чином, вказане свідчить про необхідність врахування випадкових фазових викривлень радіолокаційного сигналу в алгоритмах його часочастотної оброки у діапазоні значень їхніх статистичних характеристик

$$
\sigma_{\varphi}^{2}=1 \ldots 10 \text { pad }^{2}, \quad a=0,99 \ldots 0,9,
$$

що виникають внаслідок впливу реальних умов функціонування РЛС.

\section{Висновки}

Вплив реальних умов виконання РЛС завдань за призначенням обумовлюють виникнення флуктуацій початкових фаз радіоімпульсів прийнятої пачки. Точність вимірювання радіальної швидкості цілі суттєво залежить від статистичних характеристик фазових флуктуацій - дисперсії і кореляції, значення яких визначають умови і доцільність оптимізації часо-частотної оброки прийнятої пачки радіоімпульсів.

\section{СПИСОК ЛІТЕРАТУРИ}

1. Радиоэлектронные системы. Основы построения и теория / под. ред. Я.Д. Ширмана. - М: 3.А.О. «МАКВИС», 1999. $828 \mathrm{c}$.

2. Вопросы статистической теории антенн / Я.С. Шифрін - М:Сов. радио, 1970. -383 с.

3. Влияние среды распространения радиоволн на приморском направлении при измерении угловых координат радиолокационных целей / В.Д. Карлов, Н.Н. Петрушенко, В.В. Челпанов, К.П. Квиткин // Збірник наукових праць Харківського університету Повітряних Сил - Х: ХУПС, 2010. - № 3(25) - С. 51-53.

4. Справочник по радиолокации / Под ред. М. Сколника / Пер. с англ. под общ. ред. К.Н. Трофимова. - М: Сов. радио, 1976, T 1. - 456c.

5. Статистическая теория радиолокации протяженных целей / Р.В. Островитянов, Ф.А. Басалов - М: Радио и связь, 1982. $-232 \mathrm{c}$

6. Обнаружение аэродинамических целей в условиях шумовых и пассивных помех с широким доплеровским спектром / В.Д. Карлов, И.Г. Леонов, А.Е. Присяжный, О.Я. Луковский // Системи обробки інформації - Х: ХУПС, 2006. № 9(58) - С. 34-36.

7. Влияние тропосферы и подстилающей поверхности на работу РЛС / Н.П. Красюк - М: Радио и связь, 1988. -223 с.

8. Котов А.Ф. Влияние отражений от подстилающей поверхности на процесс локации объектов // Теория и практика систем синхронизации / Московский институт радиотехники электроники и автоматики. - М.: - 1992. - C.4-8.

9. Влияние неоднородностей рельефа позиции радиолокационной станции на эффективность подавления внешней помехи при локации надводных целей / В.Д. Карлов, Н.Н. Минервин, Н.Н. Петрушенко, Е.В. Лукашук // Системи управління навігації та зв’язку - К: ЦНДІ навігації і управління, 2008. - № 4 (8) - С. 34-36.

10. Петрушенко М.М. Особливості застосування радіотехнічних систем Повітряних Сил в нестабільних гідрометеорологічних умовах та стихійних метеорологічних явищах / М.М. Петрушенко // Системи управління навігації та зв'язку К: Центральний науково-дослідний інститут навігації і управління, 2009. - № 2 (10) - С. 54-57.

11. Влияние флуктуаций фронта помеховой волны на эффективность её подавления корреляционным компенсатором в радиотехнических системах приморского базирования / В.Д. Карлов, Н.Н. Минервин, Н.Н. Петрушенко, Е.В. Лукашук, О.Я. Луковский // Системи обробки інформації - Х: ХУПС, 2008. - № 7(74) - С. 87-93. 
12. До питання про вимірювання дальності маловисотної цілі при ії радіолокації в межах тропосферного хвилеводу над морем / В.Д. Карлов, Д.Б. Кучер, О.В. Струцинський, О.В. Лукашук // Наука і техніка Повітряних Сил Збройних Сил України - Х: ХНУПС, 2016. - № 3(24) - С. 98-101.

13. К вопросу о измерении доплеровской частоты сигнала отраженного от цели лоцируемой за пределами радиогоризонта над морем / В.Д. Карлов, А.П. Кондратенко, А.К. Шейгас, Ю.Б. Ситник // Наука і техніка Повітряних Сил Збройних Сил України - Х: ХУПС, 2014. - № 1(14) - С. 115-117.

14. Особливості вимірювання радіальної складової швидкості цілі, лоцюємої під малими кутами місця над морем / В.Д. Карлов, М.М. Петрушенко, Г.В. Пєвцов, А.І. Нос // Тези доповідей 8 наукової конференції ХУПС ім. І. Кожедуба «Новітні технології-для захисту повітряного простору», 18-19 квітня 2012 року - Х: ХУПС, 2012. - С. 295.

15. Использование фазометрического метода при оптимизации измерения радиальной составляющей скорости цели, лоцируемой за пределами радиогоризонта над морем / В.Д. Карлов, Н.Н. Петрушенко, А.И. Нос // Тези доповідей 12 науково- технічної конференції „Створення та модернізація озброєння і військової техніки в сучасних умовах”, Феодосія, 6-7 вересня 2012 року - Ф: 2012. - С. 198.

16. Использование фазометрического метода при оптимизации измерения радиальной составляющей ускорения цели над морем / В.Д. Карлов, Н.Н. Петрушенко, А.И. Нос // Тези доповідей 12 науково- технічної конференції „Створення та модернізація озброєння і військової техніки в сучасних умовах", Феодосія, 6-7 вересня 2012 року - Ф: 2012. C. 210.

17. Ошибки измерения радиальной скорости и радиального ускорения цели, обусловленные неучетом флюктуаций фаз импульсов пачки / Н.Н. Минервин, А.Л. Кузнецов // Авіаційно-космічна техніка і технологія - X: XAI, 2001. № 22 - C. $288-294$.

18. Про вплив механізму розповсюдження радіохвиль на локацію цілей в тропосферному радіохвилеводі над морем / В.Д. Карлов, О.В. Бєсова, М.М. Олещук, М.М. Петрушенко // Тези доповідей 10 наукової конференції ХУПС ім. I. Кожедуба «Новітні технології-для захисту повітряного простору», 9-10 квітня 2014 року - Х: ХУПС, 2014. - С. 254.

19. Ограничение точности измерения радиальной скорости цели за счет условий распространения, отражения и обработки радиолокационного сигнала / М.М. Мінервін, О.Л. Кузнєцов, В.А. Таршин // Збірник наукових праць Харківського університету Повітряних Сил - Х: ХУПС, 2006. - № 3(9) - С. 116-118.

20. Результати експериментальних досліджень особливостей локації маловисотних цілей, що здійснюють політ над морською поверхнею / В.Д. Карлов, М.М. Олещук, Г.В. Пєвцов, В.Л. Місайлов // Матеріали третьої міжнародної НТК «Інформаційні проблеми теорії акустичних, радіоелектронних і телекомунікаційних систем IPST-2014 - X: НTУ «ХПІ», 2014. - С. 35.

Рецензент: д-р техн. наук, проф. Л. Ф. Купченко, Харківський національний університет Повітряних Сил імені Івана Кожедуба, Харків Received (Надійшла) 12.11.2018 Accepted for publication (Прийнята до друку) 23.01.2019

\section{Ошибка измерения радиальной скорости цели вследствие влияния флуктуаций начальных фаз радиоимпульсов пачки \\ В. Д. Карлов, А. Л. Кузнецов, А. Н. Артеменко, А. Д. Карлов}

В статье рассматриваются вопросы оценивания радиальной скорости при использовании когерентной пачки радиоимпульсов применительно к случаю наличия в отраженных от цели радиоимпульсах коррелированных флуктуаций начальных фаз. Оценивается точность измерения частоты пачки для случая согласованной обработки без учета фазовых флуктуаций. Рассмотрение проводится в предположении, что на вход приемного устройства РЛС поступает аддитивная смесь отраженных от целей сигналов и некоррелированного гауссовского шума. Предполагается, что фазовые флуктуации радиоимпульсов принятой пачки распределены по нормальному закону с нулевым средним, а корреляция фазовых флуктуаций с увеличением интервала между радиоимпульсами пачки убывает по экспоненциальному или знакопеременному законам. Приведенный анализ позволяет определить условия, при которых усложнение алгоритма обработки данного радиолокационного сигнала считается оправданным.

Кл ючевы е сл ов а: когерентно-импульсная РЛС, пачка радиоимпульсов, фазовые флуктуации, радиальная скорость, гауссовский шум, радиолокационное наблюдение, эффективность оптимизации.

\section{Accuracy of the measurement of the target's radial velocity with influency fluctuations of the radio pulse burst's initial phases \\ V. Karlov, O. Kuznietsov, A. Artemenko, A. Karlov}

The article deals with the estimation of the radial velocity when using a coherent burst of radio pulses as applied to the presence of correlated fluctuations of the initial phases in the radio pulses reflected from the target. The accuracy of the measurement of the burst frequency is evaluated for case of coordinated processing without taking into account the phase fluctuations. The signals at the input of the radar's receiver is an additive mixture of signals reflected from the targets, and uncorrelated Gaussian noise, that is the assumption of investigating. It is assumed, that the phase fluctuations of the received radio pulses bursts are distributed according to normal probability laws with zero mean, and correlations of phase fluctuations decrease with exponential or alternating, sign-variable laws by increasing interval between radio pulses within the bursts. This analysis makes it possible to determine the conditions under which the complication of the processing algorithm for this radar signal is considered justified.

Keywords : coherent pulse radar, burst of radio pulses, phase fluctuations, radial velocity, Gaussian noise, radar surveillance, optimization efficiency. 